\title{
Notes on the Morphology of Ophioglossum (Cheiroglossa) palmatum, L.
}

\author{
BY \\ F. O. BOWER, F.R.S. \\ Regius Professor of Botany in the University of Glasgow.
}

With Plates XXII-XXIV.

$O^{2}$

PHIOGLOSSUM PALMATUM is the most outstanding type among the remarkable family to which it belongs. At the same time it is one of the least fully investigated. Its habitat on rotting treetrunks suggests a saprophytic tendency. Its swollen stock provides storage capacity beyond that of any other member of its genus. Its leafage, with its irregularly lobed sterile region and its varying number of fertile spikes, readily earns for it a position in a distinct section of the genus Ophioglossum, which has been styled $\S$ Cheiroglossa. Up to the present time little is known of its methods of propagation, while its gametophyte has never been observed. It was, then, with special interest that efforts were made to secure material of this peculiar plant on a recent visit to Jamaica. Certain decaying tree-trunks in the Blue Mountains on which it was known to have grown were visited. But the plant was only found in small quantity, and one plant lone was retained whole as a herbarium specimen. It is represented in P1. XXII, Fig. I, A, kindly drawn for me by Dr. A. A. Lawson, who took the specimen himself in the living state. It shows a medium, wellgrown plant, with the tuberous stock characteristic of the species, supported by numerous fleshy roots. The upper part of the stock is covered by a dense mat of pale-coloured hairs, from which emerge the two leaves. One of these is simple in form, and barren. The other is larger, and is divided into two divergent lobes, one of which shows a rudimentary third lobe. Upon the adaxial face are three fertile spikes, of which the lower two are seated as a pair side by side; the third is inserted rather higher up, and in a lateral position from the median line. A second larger specimen had a very broad leaf divided distally into three large lobes, and imperfectly subdivided again into eight minor lobes, while six fertile spikes were borne on the adaxial face. From external observation the lowest of these is approximately median; those which follow upwards are disposed right and left, 
but as regards external contours all of them are distinctly intramarginal. Their succession is not alternate, as the specimen represented in 'Studies', ii, Fig. I 22, might lead us to expect : the lower spike is slightly to the left, the second and third to the right, the fourth and fifth to the left, and sixth to the right. This is not according to the rule for pinnae, for they usually alternate. The stock of this plant, which was the largest found, was preserved for anatomical study.

It thus appears that the leaves of the two fertile specimens collected in Jamaica fall in generally as regards their external characters with those previously compared. ${ }^{1}$ There is a reasonable, though not an exact numerical parallel between the lobes of the sterile blade and the fertile spikes. The insertion of the latter is distinctly within the margin of the leaf, as defined by the strongest curvature of the surface, but there is no regularity of alternation. In the example here figured there are two fertile spikes, right and left, seated as a pair on either side of the median line. This is like what is seen in the specimen shown as Fig. II 8 in my 'Studies', ii, Pl. VIII. It is a much less common condition than that where the lowest spike is solitary and median in position.

Numerous other plants of smaller size were found, some of them very minute. By carefully rubbing down the decayed humus in which the plant was growing, Dr. Lawson was able to collect a considerable number of tubers too small to bear leaves. Some of them were attached to roots, and it is plain from a comparison of them that the plant is chiefly multiplied by buds formed on the roots of older plants, just as in other species of Ophioglossum. Fig. I, B, shows such a young plant with tuberous stock, bearing its first leaf, and still attached to the parent root.

\section{Anatomy of the Stock and the Leaf-trace.}

The anatomy of the stock of $O$. palmatum has never yet been described, so far as I am aware. Nevertheless Dr. Chrysler ${ }^{2}$ remarks of it that 'as in Ophioderma, the vascular supply of the leaf arises as several strands', and refers to my paper on $O$. simplex ${ }^{3}$ as his authority for the statement. But in that paper ${ }^{4}$ it is specifically laid down that 'the case is still open for $\S$ Cheiroglossa, in which I am not aware that the stock has been examined anatomically'. And again in the 'Origin of a Land Flora', which Dr. Chrysler also quotes in his list of literature cited, it is stated on p. 462, after a description of the way in which the strands of the leaf-trace of Ophioderma are separately inserted upon the vascular system of the stock, that 'it is still uncertain whether or not §Cheiroglossa shares this character'. I am now able to supply some data of the anatomy of the

1 Studies, ii, pp. 27-32.

3 Ann. of Bot., 1904, p. 205.
2 Ann. of Bot., I9Io, p. Io.

${ }^{4}$ p. 215. 
stock of this species, and they are in the main such as I had anticipated: their demonstration is, however, given for the first time, so far as my information goes.

The large stem investigated was about $\frac{3}{4} \mathrm{in}$. in diameter, and a little over an inch in length, bearing one large matured leaf, while younger leaves constituted a terminal bud covered in by numerous hairs. Following the trace of the large leaf downwards, it was found to consist at the base of the petiole of about twenty-five strands arranged in a ring, with their xylems all directed inwards (Fig. 2, I). This is in accordance with what has already been described for this species. ${ }^{1}$ Passing downwards, they show frequent and irregular fusions, by which their number is diminished (Fig. 2, II), but they still constitute an unbroken series across the adaxial face. In that region there is evidence of repeated fusions, which bear at first no relation to any definite break in the series. Lower down, however, the strands gather into groups right and left of the median plane of the leaf (Fig. 2, III), and these condense by further fusion into a few, and finally into two relatively large strands (Fig. 2, IV), which diverge widely apart. Following these deeper into the axis, they attach themselves to the reticulum of the axial system, their phloem naturally fusing first with it (Fig. 2, V). At this level a vascular commissure traverses the space between the points of attachment of the two leaf-trace bundles, while from the centre of this usually springs the vascular supply to a root ( $r$, Fig. $2, \mathrm{~V}-\mathrm{IX})$. In sections again lower down the fusion of the two leaf-trace strands with the axial system is seen to be complete (Fig. 2, VIII, IX), but the commissure has faded out, showing the broad leaf-gap upon the divergent margins of which the two leaf-trace strands are inserted (Fig. 2, IX). The root $(r t)$ which has been seen to be attached to the commissure above the leaf-gap is now free to pursue its course, which is usually downwards and obliquely outwards.

It is thus seen that in Cheiroglossa also, as already shown for Ophioderma, the diagnosis will apply 'petioli fasciculi numerosi separatim in rhizomae fasciculos inserti'. The number in Cheiroglossa is, however, the lowest plurality, viz. two. In this character these two sections of the genus Ophioglossum differ from all other Ophioglossaceae, in which the leaf-trace is gathered at its base into a single strand. In this they illustrate an anatomical condition which, on the basis of general comparison among the Filicales, is held to be derivative, as compared with the section of the genus designated Eu-Ophioglossum.

The numerous successive leaves of a large stock are found to behave constantly like that above described. Upon this basis the vascular system of the stock is built up. The condition accordingly seen in the upper region of the stock is as shown in the photograph, Fig. 3. Numerous roots are seen on their oblique course outwards, and the section is strewn with 
vascular strands of the leaf-traces, which at first sight appear indefinite in position. But comparison with the diagrammatized drawing in Fig. 4, in which the roots are omitted, shows that the scheme above described is adhered to. There is a central pith of moderate dimensions, round which are disposed three meristeles with their xylems directed inwards, and separated by wide foliar gaps. On either side of one of these gaps the two distinct strands of a leaf-trace (No. I) are coming away, but not yet detached. In the case of No. 2 one of the strands is detached, but the other is still connected with the meristele of the axis. In leaf-trace No. 3 both strands are clear, while that on the anodic side is already branched. It may be noted that constantly the anodic branch takes precedence in time, and is also the larger of the two. Following on through the succession of leaves-which incidentally it may be remarked show no exact regularity of divergence-the strands become wider and wider apart, owing to parenchymatous swelling, and break up into a number of strands, which behave after the manner already shown in Fig. 2.

This being the condition in an old stock, it became a matter of interest to see what is the vascular arrangement in those young buds formed upon the roots, which in default of the seedling plants may be taken as giving evidence of the ontogenetic history. The roots correspond to those of other species of the genus, in growing with a single initial cell, and in showing frequent dichotomy. On these, close to the apex, the adventitious buds arise endogenously. The details, so far as they have been observed, correspond to what has already been demonstrated by Rostowzew ${ }^{1}$ for $O$. vulgatum. The bud soon swells into an almost spherical tuber, which shows at first little differentiation, but as it grows a deep indentation becomes apparent, lined with closely grouped hairs. At the base of this is the punctum vegetationis which gives origin to the young leaves. The first of these is shown emerging from the terminal tuft of hairs in Fig. I, B.

Sections through such tubers show at first little differentiation of the turgid parenchymatous mass, but as the leaf formation is advanced the vascular system develops, and in a case where several leaves were already initiated the condition was traced from below upwards, with the results shown in Fig. 5, I-VIII. The vascular system of the bud is inserted upon that of the root from which it sprang. From the first the stele of the bud was in this case distinctly medullated, though it does not appear to be always so. Fig. 5, I, shows it at the level of its attachment to the vascular tissue of the root, the tracheides projecting right and left forming the junction with it. Externally the stele is delimited by a definite endodermis ; the xylem is, however, only poorly developed, and the phloem is hardly recognizable as such. This condition is continued upwards (II), but shortly the continuity of the xylem-ring is broken by a gap, which resembles the

${ }^{1}$ Recherches sur l'Ophioglossum vulgatum, L., Copenhagen, I89I, p. I 2. 
foliar gaps formed later (III), but in this case no strands of a leaf-trace were recognized as passing off. A little higher up a second leaf-gap appears on the opposite side of the stele, the xylem being thus separated into two equal bands, while from the middle of each of them a root-strand is given off (IV). It is at this level that the endodermis becomes indefinite, and it is not recognizable higher up. Nor is there at any point any indication of an internal endodermis. Shortly the first foliar strands are separated from the margins of the second gap (V) as two quite distinct strands, widely apart from one another in their origin, and showing further divergence as they pass outwards (VI, VII). Meanwhile the meristeles of the axis again extend, and close the leaf-gaps, so that the ring is reconstituted (VII). Other leaftraces follow after the same plan, though not with any exact or constant angle of divergence. The two strands entering a leaf soon divide up according to the plan shown for the older leaves (Fig. 2), but naturally the branching is here carried out to a less degree.

A condition is found in the lower region of the old stock above described, which may be regarded as a natural consequence of the parenchymatous swelling of it for storage purposes. As shown in Fig. 6, the pith becomes greatly distended, as compared with Fig. 3 ; the meristeles pass further apart, and the stelar condition becomes accordingly disturbed, and less readily intelligible. The large pith is traversed by a number of roots. Four of these are shown in Fig. 6, but as many as six have been observed. The roots are usually triarch, but sometimes diarch. They appear to pass into the pith from outside, traversing the foliar gaps. Though this condition is unusual, if not actually unique among the Pteridophytes, it is similar in principle to what is seen in Lycopodium Selago and some other species, where the roots traverse the softer middle cortex. In the present case all the tissues except the vascular skeleton are soft, and entry into the pith is as easy as a course through the cortex, while access to the soil is gained through the equally soft basal region of the tuberous stock.

An examination of the roots which traverse the humus in which the plant grows shows the presence of endotrophic mycorrhiza, though not in such a profuse development as the habit of the plant might lead one to expect.

Comparing what is seen in the stock of $O$. palmatum with the type for Eu-Ophioglossum, the differences appear such as would be natural in a tuberous development of that type, having a saprophytic tendency. The general development of the vascular tissue is poor, both as regards quantity of xylem and of phloem, especially the latter. The stelar construction is, however, fundamentally on the same plan, with its basket-like disposition of meristeles round a bulky pith. If the normal system of $O$. vulgatum $^{1}$ be imagined as abbreviated and distended the condition would not be unlike

1 Land Flora, Fig. 256 (5), after Rostowzew. 
that of 0. palmatum. The attachment of the roots is essentially the same. A difference of some importance is, however, seen in the leaf-trace. Whereas in Helminthostachys, Botrychium, and Eu-Ophioglossum the trace consists of a single strand springing from the base of the foliar gap, here there are two strands which originate widely apart, and laterally from the edges of the foliar gap. The leaf-trace thus divided is found also in 0 . pendulum and simplex. ${ }^{1}$ It has already been pointed out that these species, all of which are of saprophytic tendency, may be regarded as specialized offshoots of the Ophioglossaceous stock. And just as in the Ferns the single strand is characteristic of those types which may be held to be more primitive, while the divided leaf-trace is probably a derivative condition, so also here the condition seen in Eu-Ophioglossum and others of the family is probably the primitive state. This conclusion should have its bearing on the comparative study of the fertile spikes in those representatives of the genus. It should dispose us to inquire whether the elaboration of the spikes which is seen among them is not also derivative as compared with the simpler condition of Eu-Ophioglossum.

\section{MORPHOLOGY OF THE FERTILE SPIKES IN O.palmatum.}

Hitherto the development of the spike of Ophioglossum palmatum has never been described. Fortunately the terminal bud of the large plant under investigation provided two young leaves which were developing as fertile leaves, and gave the opportunity for observing early stages of the spike as seen in transverse sections of the blade (Figs. 7-IO). This has a semilunar outline, with relatively blunt margins which are unequal, one being habitually more massive than the other. The cell cleavages at the margin are of the T-type, and are repeated often with some degree of regularity at the point of greatest convexity. The result is a characteristic cell-net such as is shown in Figs. I I, I2. But this structure is most clearly seen in sections of the lamina above the insertion of the spikes. Lower down, where the margin is more rounded, the T-division still holds, but not being repeated in rapid succession the structure appears less characteristic.

It is naturally impossible to give any exact account of the segmentations involved in the origin of the spike from two leaves only, and both of them cut in transverse section. But as the details are fairly well known for $O$. vulgatum, this species will serve as a basis for comparison of the less perfect data from 0 . palmatum. ${ }^{2}$ The spilke arises as an outgrowth in which several cells appear to take part (Fig. I3). As the convexity increases, segmentation is seen which is compatible with the type described for $O$. vulgatum, having an initial cell with the shape of a four-sided pyramid. A comparison of the drawings, meagre though they are, indicates

1 Ann. of Bot., I904, p. 205.

${ }^{2}$ Compare Land Flora, pp. 447-8, Fig. $24^{6 .}$ 
that the early stages are substantially similar to those described for the Adder's Tongue (Figs. I3, I4).

As regards position upon the leaf, the lowest spike is as a rule median, though this is not without exception, as is seen in mature specimens (Fig. 7 also, 'Land Flora', Fig. $23^{8}$, D). In the younger of the two fertile leaves observed the lowest spike was perfectly median (Fig. I4). Passing upwards, younger spikes in the first stage of initiation were seen right and left, but they were distinctly intramarginal as regards the external contours (Fig. I3). It thus appears that there is an acropetal succession in the origin of these intramarginal spikes, and it is possible that the succession here seen might have been continued further had the development of the leaf been more advanced.

In the older fertile leaf the number of spikes was greater. Figs. 7-10 represent sections successively at higher levels. The lowest (Fig. 7) shows a single median spike as before. Higher up indications of at least four other spikes are seen (Figs. 8,9); they are disposed right and left of the median line, but all are distinctly intramarginal so far as the external form is concerned. One of these is represented on a larger scale in Fig. I5, and the spike appears seated at a considerable distance from the margin. It may be added that, following up the region of greatest curvature in this section into the upper region of the leaf, it is found to be continuous with that marginal segmentation already described (Figs. II, I2). One further point is worthy of note: that in Fig. 8, on the left-hand side, the section, though it is in a transverse plane, traverses two spikes. They are both intramarginal, but one more deeply than the other. In Fig. I 6 three such spikes are traversed in the single transverse section. Here the group in question lay near to the middle of the adaxial face. In point of origin it seems impossible to refer such developments, varying as they do in degree of intramarginal insertion, to the margin of the leaf. The plain fact is that, whatever the vascular connexions may be, the spikes of $O$.palmatum are in their prime origin intramarginal.

The later phases of the discussion on the morphological nature of the fertile spikes in Ophioglossum palmatum have turned so largely upon the anatomical facts that, while not neglecting other data, it is necessary at the start to be clear as to the vascular connexions. It is common knowledge that the leaf-trace in Helminthostachys, Botrychium, and Eu-Ophioglossum leaves the stele as a single strand. Already Holle ${ }^{1}$ had shown that while in Botrychium that strand divides into two equal parts, in Eu-Ophioglossum there is a central strand which maintains its identity between the lateral strands which spring from it, even up to the apex of the blade. ${ }^{2}$ The lateral strands vary in number in the different species. 
Observations have from time to time been made on the vascular supply running from the petiole to the fertile spike in Ophioglossum. Prantl showed in $O$. lusitanicum how two strands come off laterally from the marginal strands of the petiole, and unite to form the single strand of the spike. ${ }^{1}$ A somewhat similar state, though simpler still, was traced in $O$. Bergianum, ${ }^{2}$ where branches coming off laterally from the single petiolar strand fuse to form the supply of the spike. In such cases the vascular system of the spike is evidently a secondary derivative of that of the petiole. In larger species of Ophioglossum the plan is the same, only with more profuse branching. But no sufficient series of drawings has been published giving the whole story of origin of the supply to the spike, though it has been suggested for various species by several authors. Accordingly, the changes have been depicted as seen in $O$. reticulatum (Fig. 22, I-X), from which it is clear that the five strands of the spike seen in $\mathrm{X}$ arise by successive branchings and fusions from the marginal strands of the petiole, while these are themselves derived by lateral branching from the original leaf-trace strand. This is set down explicitly to meet the statement of Campbell, 'that the bundles which supply the spike are not secondarily given off from the main bundles of the petiole, but are themselves the adaxial bundles which can be traced from the base of the petiole into the spike.' ${ }^{3}$ I can only read the origin of the vascular supply of the spike in the species quoted as secondary, indicating that the spike is a subsidiary part in its relation to the whole leaf.

Passing from the relatively stable type of Eu-Ophioglossum with its single spike to those of Ophioderma and Cheiroglossa with less stability of the fertile tract, it is to be remembered that it has been shown that the leaf-trace is in them a divided one, a condition which comparison with the Ferns indicates to be probably later and derivative. This suggests that the instability of the spike seen in them is also derivative, a view which had already been developed before the anatomical facts came to hand. It has led to the seriation of the various forms already known for $O$.palmatum as showing a progression of complexity from the type of the single spike. The occasional branchings of the spike seen in $O$. pendulum are held to be incipient developments in a similar direction. ${ }^{4}$ It will now be seen how the facts of vascular supply will relate these aberrant forms with the type of Eu-Ophioglossum.

It has already been shown ${ }^{5}$ how the strands of the fertile leaf of O. pendulum form at the base a semicircle open on the adaxial side (Fig. 3 ), which, however, closes higher up (Fig. 4), and then becomes flattened as the leaf expands (Fig. 5). This is in accord with Campbell's drawings. ${ }^{6}$ But

1 loc. cit., Pl. VII, Fig. I.

2 Studies, ii, p. 68, and Land Flora, p. 463.

3 American Naturalist, vol. xli, No. 483 , p. ${ }_{5} 57$.

- See Studies, ii, p. 28, \&c., and Land Flora, p. 435, \&c.

${ }^{5}$ Ann. of Bot., I 904, Pl. XII, Figs. 3-5.

${ }^{6}$ loc. cit., p. I 54 , Fig. I 3 . 
it is necessary to be clear how complete the fusion of the marginal series is on the adaxial side. This is shown in Fig. $2 \mathrm{I}, a, b$, from which it appears that all possibility of discriminating between the confluent marginal strands is lost. The supply to the spike is afforded by the median adaxial region of the flattened circle. The same is the case with 0 . intermedium, ${ }^{1}$ but here the actual coalescence of the marginal strands appears to be delayed till the base of the spike is reached, while the proportion of the strands of the fertile to those of the sterile region matches the relative size of those parts. It may be concluded from my own drawings of $O$. simplex that the condition there is in principle the same. ${ }^{2}$ Hence it is seen that the identity of the margins as marked by the vascular strands is entirely obliterated, while the vascular supply to the spike in Ophioderma comes off from the indeterminate vascular supply on the adaxial side of the petiole.

Turning now to Cheiroglossa, in the leaf-stalks of the weaker and first-formed sterile leaves the margins as defined by the vascular strands are widely apart, which is naturally in accord with their flattened form. But as the plant strengthens and works up to the production of propagative organs the leaf-stalks become more nearly cylindrical, while the marginal strands come nearer together, till in the fertile leaf they constitute a complete circle (Fig. 2, I-III). Frequent fusion of strands is seen on the adaxial side, so that the identification of the margins by means of the strands is quite impossible. This obliteration of the margins takes place close to the leaf-base, and it is far above the point where it occurs that the fertile spike or spikes arise. The source of their vascular supply has been indicated for a case where there were three spikes, the lowest of them median. ${ }^{3}$ But fresh drawings have been made from the old sections, giving the details more satisfactorily (Fig. I7, I-IX). From these it is seen that the supply to the lowest spike, which was median, comes off from the adaxial region of the circle of strands, where the marginal characters had been completely obliterated by the repeated fusions during their course through the elongated cylindrical petiole (I, II). By the passage of the median strands outwards the remainder of the strands appear ranged in a semicircle (III). Fig. I 7, III-VII, shows successive steps in the separation of the vascular supply for the two higher spikes, which are borne right and left. The origin of the strands is by segregation from the margins of the semicircle ; it may, however, be noted that their derivation is not by any uniform scheme, though the number ultimately arrived at is in each case three. The sections show further that at the level of separation of the spikes their position on the leaf was intramarginal (VII-IX). It is worthy of note as having some bearing on their morphological character that the number of

1 Campbell, loc. cit., p. I53, Fig. I 2.

2 loc. cit., Figs. $24-9$.

3 loc. cit., Pl, XII, Figs. I4-23. 
strands traversing the stalk in all the three spikes is equivalent, the number being three, of which the median strand is the largest.

As the knowledge of the vascular supply to the spikes in $O$.palmatum is still very limited, being hitherto restricted to the above observations together with a very imperfect representation of similar facts by Bertrand, ${ }^{1}$ the portion of the large dried specimen described above, bearing the two highest spikes, was cut out (Fig. 18). After swelling with caustic potash it was halved, embedded, and cut into sections. These provided the essential points in the origin of their vascular supply. Fig. I9 shows successive sections from below the spike to the left in Fig. 18 . It will be seen that the marginal strand from the leaf passes directly into the stalk of the spike without any complications. The next intramarginal strand does the same, but just before the separation of the stalk from the leaf a vascular commissure runs across, almost transversely connecting it with the third strand from the margin of the leaf (IV). On complete separation of the stalk, a third strand, but weak and imperfectly developed, is seen in the section of the stalk $(\mathrm{V})$, occupying the place of the lateral strand as seen in Fig. I 7 (VIII-IX). Evidently the vascular system of this spike, which is small, is incompletely developed as compared with the larger examples. The still smaller spike on the right-hand side, which was the highest borne on this leaf, showed the vascular connexions seen in Fig. 20 (I-VII). Here the small marginal strand of the leaf first fuses with the rather stronger strand next adjoining it (I-III). This then passes out into the base of the spike (IV), and subsequently separates again into two (V); then a vascular commissure, as in the previous example, passes from the next inner strand almost horizontally outwards to join it (VI). The stalk then separates from the leaf (VII), its vascular supply being represented in its further course up the spike by a single band-shaped strand, which shows signs of being composed of three strands as in other cases. It may be held to be a reduced example of the same type of structure.

A careful comparison of the five examples thus described shows that in no two of them are the vascular connexions at the base of the stalk exactly the same, though the structure of the stalk is essentially alike in them all, allowance being made for their varying size. These facts indicate two things. First, that the spikes are probably all morphologically equivalent parts. Secondly, that their attachment is not according to strict rule, a condition that readily accords with the interpretation put upon them in my 'Studies'.' They were there held to be referable in origin to interpolation or chorisis of a single spike, in which case their position would not necessarily be regular. It would then be natural to expect less regular vascular connexions than in the case of parts produced in the normal sequence. A comparison of the specimens here described with those figured in

\footnotetext{
1 Travaux et Mémoires de l'Université de Lille, t. x, Mém. 29, Fig. 97.
}

2 ii, pp. 43,44 . 
'Studies', ii, Figs. I20-I 29, indicates that greater variations still may occur in the vascular connexions of the spikes than those above noted.

In order to check my former statements and verify the drawings, a re-examination has been made of the specimens at Kew. This confirms the accuracy of the description and drawing already given as Fig. I20, in point of the insertion of the median branched spike which it shows; its vascular connexion also is clearly intramarginal relatively to that of the lower-lying, but more marginal spikes. The specimen of Miers from S. Brazil, represented in my Fig. I2I, was also re-examined. I state specifically that my former representation of it is substantially correct. The spike fourth from above is inserted in an almost median position, and its vascular connexion, which can be quite easily followed since the specimen is young and transparent, runs internally (i. e. more near to the median line), as compared with those of the next two spikes on the right, which are more marginal in insertion. To show that these are not isolated cases, it may be stated that there is a second specimen at Kew, also collected by Miers from S. Brazil, very like that of Fig. I2I, bearing two spikes in approximately a median position: these are the fifth and sixth counting from below, and they are inserted between those which are lateral, and they have their vascular connexions visibly joining a strong strand which runs up the median region of the leaf. This strand lies clearly in a more median position than the vascular connexion of the next lower lateral pinna.

Another specimen collected by L'Herminier, but without locality, shows on a leaf bearing ten spikes a median insertion of the spike sixth from the base ; those directly below it are inserted right and left of it, one of them being branched. At almost the same level as this median spike are other lateral spikes, while the vascular connexions, which are readily recognized in the dried condition of this specimen, pass internally to those of the next lower marginal spike. This is again a clear case of intramarginal insertion, with the vascular connexion also intramarginal relatively to that of a lower spike. It is to be noted that these examples of pronounced intramarginal insertion are all seen in cases where the spikes are numerous. It is precisely in such cases that the clearest departure from the marginal position would be probable if the origin of the plurality of spikes were by some process of interpolation or chorisis.

Dr. Chrysler, in his paper, ${ }^{1}$ makes certain deprecatory remarks on 'inspection of the external surface'. This is at least better than no examination at all. It is to be borne in mind by those who criticize, that specimens in the Herbaria of Kew and the British Museum cannot be cut up at will. Nevertheless, evidence from examination of them without cutting them into sections, though neither final nor so convincing as this would be, has its value. It cannot be summarily dismissed, however great may be the 
preference for evidence by sections. But Dr. Chrysler has not only ignored the evidence afforded by my drawings, ${ }^{1}$ he has also neglected the theory which was based upon them. This theory is not even mentioned by him. But on the basis of observations on other genera, combined with the citation of my own observations on a certain specimen of $O$. palmatum above quoted, ${ }^{2}$ he concludes that 'according to the reasoning here employed it may be inferred that the lowest spike in this specimen represents two fused lobes of the leaf, while the next two spikes represent single lobes'. He continues thus: 'Bower lays much stress on the observation that the spikes do not generally arise from the margin of the leaf, yet the only transverse sections which he figures $(6, p .463)$ clearly show that in the case of the three spikes so represented, the origin of the vascular supply at any rate is truly marginal, i. e. derived from the free edges of a curved leaf-trace made up of a number of separate strands. Probably most morphologists would place more reliance on the disposition of the vascular skeleton than on the superficial "flesh" which clothes the skeleton."

This rough and ready way of deciding a rather intricate morphological problem will hardly commend itself to morphologists who take other facts besides those of vascular anatomy into their view, least of all to those who have personally examined a large series of specimens of 0 . palmatum. Most morphologists have little or no personal knowledge of the plant in question, and Dr. Chrysler does not bring any evidence that he has studied specimens of it himself. Under these circumstances it would only be reasonable to expect some degree of reticence in amending conclusions which are explicitly based upon examination of a large series of specimens. In explanation of the facts derived from such study in 1896 , a theory of chorisis or duplication was advanced. ${ }^{3}$ But as this theory is not criticized, but passed over in silence by Dr. Chrysler, it seems necessary to state it afresh, and to recapitulate the reasoning upon which it is still held to be the correct interpretation of the facts for O.palmatum.

It is found in such normal types of Eu-Ophioglossum as O. vulgatum that the spike is susceptible of occasional branching, especially when the conditions are hypertrophic. ${ }^{4}$ In $O$.pendulum the branching is more frequent, and sometimes involves the lower sterile stalk of the spike (Figs. I $30-2)$. It was suggested that the condition which appears as an occasional hypertrophic abnormality in $O$. vulgatum became frequent in $O$. pendulum, and has become fixed as an almost constant condition in wellnourished plants of $O$. palmatum. The comparison was drawn with those Angiospermic flowers in which an increase in number of the parts from the probable primitive type is referable to interpolation or chorisis. Comparison may be made with the androecium of Hypericaceae, Malvaceae, or Rosaceae.

\footnotetext{
${ }^{1}$ loc. cit., Figs. I $20-9$.

${ }^{3}$ loc. cit., p. 43 ; see also Land Flora, p. 439.

2 Ann. of Bot., I904, Pl. XV.

${ }^{4}$ Studies, ii, Figs. I 33, I34.
} 
Some indication of a like process is seen in the Sphenophyllales, while it is not going too far to trace a distant parallel in the spread of the sori over the enlarged leaf surface in many phyla of Ferns. The following are the facts and considerations which make me think that we may find in duplication in its widest sense, or pleiogeny, ${ }^{1}$ as it might better be termed, the correct interpretation of the peculiarities of $O$. palmatum.

I. Frequent branched conditions of the fertile spike occur in $O$.palmatum. This is especially common in specimens where the number of spikes is large ('Studies,' ii, Figs. I20-9). The details in some of the spikes near the margin in $O$. palmatum are closely similar to the branchings observed in $O$.pendulum, in cases where the single though branched spike is inserted in a median position ('Studies,' ii, Figs. I 3 I, I 32 ). Thus the branching is not a feature of the median spike only, nor is the branching always a simple bifurcation, as Dr. Chrysler's interpretation would demand.

II. A parallelism has been traced between the number of the lobes of the sterile leaf and the number of the spikes in $O$.palmatum, showing that the number of the fertile spikes bears a general relation to the nutritive leaf area. As the plant grows stronger the higher complexity in both regions is attained. There are signs of a like though less exact parallelism in $O$. pendulum. These facts readily accord with a theory of pleiogeny.

III. Certain specimens have been described, such as those shown in 'Studies', ii, Figs. I20, I2 I, which are difficult to harmonize with any pinnatheory, though they fall in readily enough with a theory of pleiogeny. They show certain of the higher-seated spikes in an approximately median position, nearer, in fact, to the centre than others which are almost at the same level but more nearly marginal in their insertion. The vascular connexions of these have not been examined by sections, but the specimens are often sufficiently transparent to give opportunity for tracing them, and from such evidence it seems highly improbable that they would turn out to be constantly marginal like the rest.

IV. The superficial origin of the spikes upon the adaxial face of the leaf is now demonstrated developmentally, and even the later spikes of the leaf have, so far as observed, an intramarginal insertion (Figs. 8, 9, I3, I 5), while numerous cases can be quoted where the spikes show no regular alternate arrangement as pinnae usually do.

V. The identity of the margins of the leaf, so far as these are defined by the vascular strands, is entirely merged by the repeated fusions of the strands on the adaxial face of the elongated petiole. It is, therefore, a question how far the marginal strands above the first spike really represent the original (phyletic) margins to which normal pinnae might be referred.

VI. Dr. Chrysler, following and extending the observations of Bertrand and Cornaille, has shown that marginal vascular origin is not a necessary

\footnotetext{
${ }^{1}$ See note explaining this term, p. 296.
} 
criterion of pinna-nature within this family, for the supply both to spikes and to pinnae may be intramarginal. It may then be doubted how far a mere marginal origin of the vascular supply can be used as a criterion of pinna-nature, as Dr. Chrysler does in the present case. It cannot be accepted as outweighing other considerations, such as arise from comparison based on a large series of specimens.

VII. It has been shown that the vascular supply to the median spike in the leaf examined in 1904 consists, like that of the succeeding two spikes, of three strands, of which the median one is the largest. All the three spikes are in fact equivalent in this respect (Fig. I 7, I-IX). Dr. Chrysler's suggestion on the basis of the vascular connexions alone is 'that the lowest spike in this specimen represents two fused lobes of the leaf, while the next two spikes represent single lobes'. The fact that the vascular supply to all of these is equivalent in all except the source, being in the one case median, in the others marginal, should carry some weight with vascular anatomists, raising a doubt of the validity of the conclusion. The vascular supply to two fused pinnae might be expected to be more complex than that to a single lobe. On the other hand, the structure actually observed is such as might be expected on a theory of pleiogeny.

VIII. The species which show the peculiarities under discussion belong to the two sections of the genus generally admitted to be specialized. It is in such forms that one may most readily expect developments which will diverge from the usual type and follow a line of their own. Both species are partially saprophytic, a condition often associated with unusual developments, reducible with difficulty to the ordinary schemes of construction. In plants biologically so restricted as these half-saprophytic dwellers on decaying trunks and humus a large spore-output is almost a necessary condition of survival, or at least of spread. This utilitarian reason for amplification is easily intelligible, and the ready means appears to have been amplification and irregular lobing of the sterile lamina, and repetition of the fertile spike. Both of these were probably special and phyletically late occurrences. There seems to be no reason to hold that they should necessarily be retrospective developments. Dr. Chrysler appears to assume that they were. I have suggested, on the other hand, that both the sterile and the fertile regions of the leaf have progressed along new lines of development, and that their parts are not necessarily reducible to terms of pinnae such as are seen in the pinnate members of the family.

The conclusion arrived at may be summed up as follows. The spike of Eu-Ophioglossum is regarded as the unit upon which further development has played. The facts, both developmental and anatomical, fall in readily with a theory of amplification of that unit, or pleiogeny, as explaining the complex forms observed in $O$. pendulum, and more pronouncedly in $O$. palmatum. The sterile lamina enlarged and formed irregular lobes, 
which are not held as pinnae in the usual sense of the word. The spikes underwent a parallel pleiogenetic amplification. Sometimes this amplification took the form of repetition of spikes like the original one, but seated at points apart: this is duplication or interpolation. Sometimes two spikes are seated near together, or upon a common stalk; in the latter case they may merely show distal branching. These are conditions indicative of chorisis. Other variants may also be found. But in all these amplifications the spike is the unit throughout, and the branchings are not to be interpreted in terms of pinnae as normally understood.

\section{Morphology of the OphioglossaceOUs SpIKe.}

The above discussion has been concerned with the more elaborate types of the spike-development in the genus Ophioglossum. It has not touched the question of the morphology of the spike itself, which has been held as the unit in the amplifications seen in Ophioderma and Cheiroglossa. In my 'Studies. II. Ophioglossaceae (1896)', the evidence up to that date was summarized and weighed with a view to tracing the probable affinity of the family, and incidentally the morphological character of the fertile spike which is its most notable feature. This required a careful balancing of evidence for and against alternative views. Of these the one indicated affinity with the Sphenophyllales and Lycopodiales, the spike being regarded as a result of amplification from the sporangiophore, or ultimately from the sporangium. The alternative indicated an affinity with the Filicales, in which case the morphology of the simple spike would be referable in some form or another to a pinna or a coalescence of pinnae. The evidence up to 1896 appeared to me to favour the former alternative, and that conclusion was stated with ample illustration and discussion of the details on which it was based.

Since then considerable advance has been made in various directions which bear upon the question. The researches of Lang ${ }^{1}$ and of Bruchmann ${ }^{2}$ have greatly increased the knowledge of the gametophyte and of the embryology. The discovery by Lyon ${ }^{3}$ of the suspensor in Botrychium obliqum (followed recently by the description of a like body in Helminthostachys by Lang ${ }^{4}$ ) at first sight appeared to strengthen the Lycopod affinity, but the demonstration of a like organ in Danaea by Campbell ${ }^{5}$ put matters back in statu quo.

A second line along which recent advances affect the question is the anatomy of some of the earlier types of the Filicales. Kidston and GwynneVaughan, by comparison of fossils which are plainly of Osmundaceous alliance, whether or not they are Osmundaceae in the modern sense, have shown it to be highly probable that the structure seen in the modern Osmundaceous stem is in the main the result of an up-grade development with medullation from a protostele. This has paved the way for similar

\footnotetext{
1 Ann. of Bot., xvi, 1902.

2 Bot. Zeit., I904, and Flora, I906.

3 Bot. Gaz., Dec., 1905

4 Ann, of Bot., 19Io, p. 6II.

5 Ann. of Bot., I909, p. $69 \mathrm{I}$.
} 
comparisons in the anatomy of the Ophioglossaceae, and the analogy between the vascular condition of the Ophioglossaceous stock and that of Thamnopteris, for instance, ${ }^{1}$ is, to say the least, very suggestive.

In the next place, the work of Bertrand and Cornaille ${ }^{2}$ has shown that the origin of the vascular supply to the pinnae in certain relatively primitive Ferns was intramarginal on the abaxial side. This line of inquiry has been followed up by Chrysler, ${ }^{3}$ and applying it to the Ophioglossaceae, he has demonstrated that in Botrychium virginianum the intramarginal origin holds not only for the sterile pinnae, but also for the fertile spike. He concludes from this and other facts that the normal spike is the result of fusion of two basal pinnae. In fact, he upholds the old theory of Roeper, and maintains that the Ophioglossaceae are related to the Ferns, and especially to the Osmundaceae and Marattiaceae, springing from a primitive stock at a remote period. But in arriving at this conclusion, Dr. Chrysler does not, in his own observations, travel over ground outside that of the anatomy of the leaf, combined with a comparison of external form of certain abnormalities in B. obliquum. This is a rather hazardous course in such questions. While due weight must be accorded to his anatomical results, his conclusions must stand the test of reference to other sources of information before they can be considered as amounting to more than interesting suggestions. ${ }^{4}$

It must be admitted that since 1896 the trend of the evidence has been decidedly such as to strengthen the Filical alliance of the family. This follows in the first place from the comparison of the gametophyte, when due allowance is made for the similarity of underground habit which they share with the Lycopods having led to a probable parallel development. It comes out also in some degree (which recent work on the Osmundaceae and Botryopterideae has distinctly strengthened) in the anatomy of the stock. Lastly, the observations of Dr. Chrysler have contributed in marked degree to strengthen the comparison with Ferns on the basis of the anatomy of the leaf. All this indicates that a reconsideration is necessary of the LycopodSphenophyll-alliance previously recognized for the Ophioglossaceae. But before coming to a definite conclusion there are three other points to be taken into our view, two of them favourable, the other adverse to the Fern alliance. In the first place the comparison has been made in previous discussions with the Sphenophyllales (including Psilotaceae) in respect of the behaviour of the sporogenous cells. It was pointed out that in the Psilotaceae a proportion of the spore-mother-cells became abortive before the tetrad

${ }^{1}$ Fossil Osmundaceae, Part iii, Pl. I.

${ }^{2}$ Travaux et Mémoires de l'Université de Lille, x, Mém. 29. ${ }^{3}$ Ann. of Bot., I9ı.

4 The recognition of affinity of the Ophioglossales with certain early Filicales is no new conception. It was indicated in unmistakable terms by Renault in 1875 (Ann. Sci. Nat., Sér. 6, tom. i, pp. 232-4), while Prantl, in I884, pointed specifically to the Botryopterideae and the Osmundaceae as possible lines of relationship with the living Ophioglossaceae (Beitr. z. Syst. d. Ophioglosseen, p. 345). See also Scott, Studies in Fossil Botany, ii, p. 640. 
division, acting as a diffused tapetum. In the Memoir of $1895^{1}$ the results of Rostowzew were accepted, without sufficiently critical examination of my own preparations, as showing that in Ophioglossum also cells scattered through the sporogenous group became disorganized without undergoing tetrad division. It has since been found that this is not so, ${ }^{2}$ and accordingly the comparison with the Psilotaceae on this feature falls away.

Secondly, the comparison with the Psilotaceae-Sphenophyllaceae alliance was also based on the method of insertion of the sporangiophore on the adaxial face of the leaf. But it now appears that the similarity does not extend to the mode of origin of the vascular supply to the fertile regions in the plants compared. Dr. Chrysler has laid weight upon the marginal attachment of the vascular supply to the spike. The fact is now quite plain that, with certain possible exceptions in the specialized O.palmatum, the supply comes off in the Ophioglossaceae either from the margin of the petiolar system, or on the abaxial side from an intramarginal gap. It may be seen, on the other hand, in any series of sections of the sporophyll of Tmesipteris that the marginal portions of the strand of the leaf-stalk pass off right and left into the leaf-lobes, while the central portion enters the synangium. The origin of the supply to the sporangiophores in Cheirostrobus is described as coming off from the middle strand that supplies the sterile region of the leaf, by a branching, so that one of its branches lies above and inside the other. ${ }^{3}$ That is, the origin is median and adaxial. A similar branching appears to be the rule also for Sphenophyllum. These facts indicate a real difference between the marginal or slightly abaxial origin of the vascular supply to the spike in the Ophioglossales, and the median adaxial supply to the sporangiophores in the Sphenophyllales, which if it prove to be constant will strengthen the alliance of the former with the Filicales. It is of course a possible view, which might be based on the mere anatomical facts, that in Tmesipteris the synangium represents the whole terminal region of the leaf, which has remained fertile, as in Osmunda regalis. But against this are the facts of development $;{ }^{4}$ moreover, that explanation would not fit for Sphenophyllum or Cheirostrobus. For these reasons I prefer to accept the anatomical distinction as a real and a valid one.

On the other hand, one of the most impressive features in the Filicales is the extraordinary constancy of the progression by which the sporangium suffers reduction in size and complexity of structure, in the thickness of its gradually elongating stalk, and in the numerical output of its spores as we pass from the more primitive to the more specialized forms, while the precision of the mechanism for scattering them increases. This matter has been treated at length in the 'Land Flora' (pp. 637-46, \&c.). But if the

1 p. 20.

2 Compare Land Flora, p. 45 I, Fig. $25^{\mathrm{I}}$.

3 Scott, Phil. Trans., Series B, vol. clxxxix, p. I 2.

4 Land Flora, p. 4I 4. 
Ophioglossales were derived from a primitive Fern stock, and the sequence be, as the anatomical comparison indicates, from a type like Botrychium virginianum with relatively numerous smaller sporangia through types such as B.ternatum and Lunaria with fewer and larger sporangia, to Ophioglossum itself, it is plain that we are contemplating a progression which is the direct converse of that illustrated by the Ferns at large. Such a progression is of course possible. The question is whether it is probable. The apparent improbability of it weighed with me strongly in previous discussions on the phyletic position of the Ophioglossales.

There is, however, a further circumstance which makes this difficulty less serious than it at first appears. It lies in the fact that in Ophioglossum a single initial cell is found at the apex of its stem and root. The leaf-apex and the structure of its margin, on the other hand, approaches that of the Marattiaceae, and is in accord with the bulky sporangial structure. A comparison may be drawn of the meristematic conditions seen in the various groups of Ferns. ${ }^{1} \quad$ In the Marattiaceae all the segmenting parts are bulky and complex in their cleavages; in fact the centre of construction lies deep. In the Osmundaceae a middle position is seen between the state of the Marattiaceae and that of the Leptosporangiate Ferns, and this applies here also to all the segmenting parts. In the Leptosporangiate Ferns themselves a more definite scheme of cleavage is found in all the meristems, which is in accord with the definite segmentations of the attenuated sporangium; in fact in them the centre of construction is more superficial. In all of these the various parts share the character consistently of a definite or a less definite reference to single initials. But the Ophioglossaceae show a discrepancy which does not find its match in any of the true Filicales. For the leaf and sporangium resemble the Marattiales in their more complex cleavages, while the apices of stem and root have each a single initial as in the Leptosporangiate Ferns. This discrepancy might be referred either to a progressively more bulky modification of the leaf and sporangium in a plant derived from a type resembling the Osmundaceae, or to a conservatism by which the plant has retained the characteristics of some remote ancestry in its leaf and sporangium, while the axis and root have taken on the characters of later forms. In view of the peculiar biological conditions of the family, and especially of the tendency towards saprophytism in the genus Ophioglossum, I am inclined to the former alternative, and to look in the direction of the Osmundaceae and Botryopterideae for the nearest relatives of the Ophioglossaceae.

There are various other comparative points which indicate collectively a relation, however distant, with early types of the Filicales rather than with the Sphenophyllales, such as the hairiness in the apical region, especially as seen in $O$. palmatum, the conformation of the leaf-base and the vascular 
structure in the family at large. But these must be left over at the moment. It is obvious that there are difficulties in assigning any definite place to the family at present. But sufficient has been said to show how clearly the balance of evidence is setting in the direction of an alliance of the Ophioglossales with the early Filicales.

A natural consequence of adopting a Filical alliance for the Ophioglossaceae would be a recognition of the pinna-nature of the spike, probably in most cases with a coalescence of two pinnae as in the old theory of Roeper. I should, however, attach less weight in arriving at this conclusion to such abnormalities as those quoted by Dr. Chrysler than he appears to do. ${ }^{1}$ For branchings of very various character may be found, which all deserve equal consideration with those which support a hypothesis of fusion. The analogy with the Marsiliaceae also becomes obvious. But probably the condition there seen is an instance of parallel development, and arises along a different phyletic line. For the two families belong to distinct types of Ferndevelopment. The Ophioglossaceae appear to be naturally referable to the Coenopterid $^{2}$ type, characterized by less definite specialization of the sporangium. But the Marsiliaceae are pronouncedly Leptosporangiate, and, as Campbell has so convincingly shown, their relations appear to be in the direction of the Schizaeaceae. ${ }^{3}$

\section{SUMMARY.}

I. The tuberous stock of Ophioglossum palmatum is traversed by a stele showing a bulky central pith and transversely widened leaf-gaps. It is of the same type as Eu-Ophioglossum.

2. The leaf-trace originates as two distinct strands inserted widely apart, right and left of the leaf-gap.

3. The spikes originate like that of Eu-Ophioglossum. The lowest is usually median, but not always. The insertion of the rest is usually intramarginal, and shows no regular alternation. The spikes branch frequently and irregularly.

4. The facts indicate that the spike of Eu-Ophroglossum is the morphological unit, and that the conditions seen in less degree in $O$.pendulum, and more clearly in $O$.palmatum, are due to 'pleiogeny', that is an increase from that unit in various ways, such as by partial or completed branching, or by interpolation of accessory spikes. The numerous spikes of $O$. palmatum are not then directly referable to normal pinnae, any more than are the irregular lobes of its sterile lamina.

5. Phyletically $O$.pendulum, intermedium, and simplex form a derivative series from Eu-Ophioglossum. ${ }^{4} \quad$ O. palmatum represents a parallel, but probably a distinct line, which has carried amplification of the leaf further.

\footnotetext{
1 loc. cit., pp. 7-9 and Pl. II.

2 Seward, Fossil Plants, ii, p. 433.

3 Campbell, American Naturalist, xxxviii, 1904, p. 761.

4 See Land Flora, p. $44 \mathrm{I}$.
} 
The divided leaf-trace which they all show confirms the derivative character of both lines.

6. The balance of evidence acquired since 1896 has distinctly favoured an alliance of the Ophioglossaceae with the Filicales. It is in the direction of the Coenopterideae, and of living Ferns the Osmundaceae, that we may look for their true place.

7. The normal spike of the Ophioglossaceae will, in relation to this comparison, and especially in accordance with the anatomical facts, be held to be ultimately of pinna-nature ; perhaps in most cases a result of pinnafusion, according to the theory of Roeper. But this unit is subject to repetition in Ophioglossum palmatum.

8. The vascular supply to the Ophioglossaceous spike being normally marginal, or from an abaxial pinna-gap, it differs from that to the sporeproducing organ in the Psilotaceae and Sphenophyllaceae, where it comes off from the adaxial face of the foliar strand, or is the middle region of it. This difference, if it be found to be constant, may provide a real and valid anatomical distinction.

\section{NOTE.}

I know only too well the undesirableness of introducing new terms into the vocabulary of the science. But any one who has read attentively those interesting pages of Professor Goebel's 'Organography' in which he deals with the phenomena of increase and decrease in number of parts in the flower ${ }^{1}$ must have felt the want of some expression which, without connoting any detailed view as to the method, shall still convey the conception of increase or decrease in number of the parts from that which is regarded as normal or typical. The old terms 'chorisis', 'dédoublement', 'fission', or 'splitting', all have had special applications, and convey meanings relating to the method or manner of the increase. In the use of them there is a danger of conveying more than the simple conception of increase. 'Negative chorisis' and 'ablast' suffer under the same disability. The readiest way of avoiding such difficulties is by the introduction of some new term which carries no preconceptions, and while stating the fact does not imply any method. I venture therefore to suggest that the term 'pleiogeny' should be used to connote those phenomena which involve increase in number of parts beyond the normal or typical. The term 'meiogeny' would similarly connote a decrease from the normal or typical.

It is not only in the case of floral structure that such terms may apply. In the present case it would be a phenomenon of 'pleiogeny' that we have been studying in Ophioglossum palmatum. And similarly the increase of sori so frequently traceable in Ferns would be a phenomenon of the same class. Having recognized this, the next step will be by comparison and 
analysis to decide the method by which it is brought about. It will then appear that more than one method may be involved in any given example. For instance, where one primordium is already initiated, and the activity of tissue-formation becomes localized at more than one centre in relation to it, thus producing more than one part in place of the original one, the method of the pleiogeny would be chorisis. But if two centres of activity originate apart from one another where usually only one exists, or if an additional one appeared in a position usually untenanted, that would be interpolation. But both would fall under the general expression of pleiogeny.

\title{
DESCRIPTION OF FIGURES IN PLATES XXII-XXIV.
}

\author{
Illustrating Prof. Bower's paper on Ophioglossum palmatum.
}

Fig. I. A, Fertile plant of Ophioglossum palmatum represented complete, about three-quarters of the natural size, from a drawing by Dr. A. A. Lawson. B, A bud inserted upon its parent root, showing the tuberous stock $(t)$, surmounted by a dense tuft of hairs $(h)$, and a single young leaf. $\times 2 \frac{1}{2}$.

Fig. 2, I-IX. Successive transverse sections of a leaf-base, following the leaf-trace strands downwards to their insertion on the stele. I and II show the very numerous small strands, forming a more or less circular series, with frequent signs of fusion across the adaxial face of the petiole. III and IV show stages of segregation of the strands into two lateral groups, which in V and VI have united into single strands. $\mathrm{V}-\mathrm{X}$ show the successive stages of insertion of these, right and left, at points widely apart upon the margins of a leaf-gap. In V-VII a commissure of the vascular network is seen just above the leaf-gap, and from the middle of it arises a root $(r t)$, which takes its course obliquely outwards (VII-IX). The leaf-trace strands do not fuse completely with the meristeles of the axis till the level of the gap is reached (VIII, IX). $\quad \times$ about 6 .

Fig. 3. Photograph of a transverse section through the old stock, about half-way down its length, showing centrally the pith surrounded by three meristeles. From the edges of two of these a leaf-trace is coming off, as in Fig. 2, VIII. Externally numerous leaf-traces in various stages of advance are traversing the bulky cortex, and several roots are also seen. $\times 4$.

Fig. 4. A slightly diagrammatized key to the vascular system shown in Fig. 3. The roots are omitted for clearness, while the several foliar traces are connected by dotted lines and numbered. It will be seen that they conform to the stages shown in Fig. 2; also that the divergence between the successive leaves is not a constant one.

Fig. 5, I-VII. Successive transverse sections of the stock of a young adventitious bud. I shows the insertion on the vascular system of the parent root; II, the vascular ring surrounding the central pith, which is present from the first. In III the ring opens, but no leaf-trace was given off from the gap. In IV the ring has opened on the opposite side also, while each vascular meristele is giving off a root-trace. The first leaf-trace is shown coming off in $\mathrm{V}$, as two separate strands from the edges of the second gap. In VI the strands are separated, but the first gap has closed again by a vascular commissure. In VII the second gap has also closed, reconstituting the ring, while the strands of the trace are diverging widely. Drawn freehand. $\times$ about 50.

Fig. 6. Photograph of a transverse section of the old stock near to its base, showing the pith greatly dilated, the meristeles separated, and stretched transversely, while four roots are traversing the pith; others are seen in the cortex. $\times 4$. 
Figs. 7-10. Photographs of successive transverse sections thiough a young fertile leaf. Fig. 7 is at the level of insertion of the lowest spike, which is seen to be median. Fig. 8 shows four spikes in two groups, right and left of the median plane. Fig. 9 shows a higher section traversing two spikes only, which are clearly intramarginal. Fig. Io is a transverse section of the leaf above the spikes, showing projecting margins similar to those already seen in Fig. $9 . \quad \times 4^{8}$.

Figs. I I, 12. Detail of segmentation of the marginal region of a fertile leaf, showing the T-type of division, but not with constant results. $\quad \times$ I 25.

Fig. I3. A very young spike, as seen in a transverse section of the parent leaf, from which it arises in an intramarginal position. It results from the outgrowth of a number of cells. $x$ I 25.

Fig. 14. A spike from the same leaf, but lower down, and inserted in a median position. It shows a rather more advanced state, thus indicating that there is an acropetal succession in the formation of the spikes. $\times 125$.

Fig. I5. Transverse section from an older leaf, showing a young spike in a distinctly intramarginal position. $\times 125$.

Fig. 16. Transverse section of the middle region of a fertile leaf, cutting obliquely through the insertion of three spikes. This indicates the irregularity of their position while young. $\times$ I 25.

Fig. I7, I-IX. A series of fresh drawings from the sections of the fertile leaf described in the 'Annals of Botany', I904, p. 210, Pl. XV. Figs. I-III show the origin of the vascular supply to the lowest median spike. Figs. IV-IX show the same for the two lateral spikes. It will be noted that in either case the number of the strands is ultimately three.

Fig. 18. Portion of the leaf of the large dried specimen from Jamaica, bearing to the left the fifth spike, and to the right the sixth, the latter being the smaller. The transverse sections of their stalks are also shown; the fifth is traversed by three strands, the weaker sixth only by one. $\quad \times 2$.

Fig. 19, I-V. Successive transverse sections showing the origin of the vascular supply to the fifth spike.

Fig. 20, I-VII. Successive transverse sections showing the origin of the vascular supply to the sixth spike.

Fig. 2 I $a, b$. Transverse sections through the petiole of 0 . pendulum, $a$, lower down, $b$, higher on the same part,. showing how completely the margin as marked by vascular characters is obliterated. Drawn freehand.

Fig. 22, I-X. Successive transverse sections through the petiole of 0 . reticulatum, showing origin of the vascular supply to the fertile spike. Section I is the lowest. Drawn freehand. 
Arnals of Botary,

Vol.XXV. Pl.XXII.

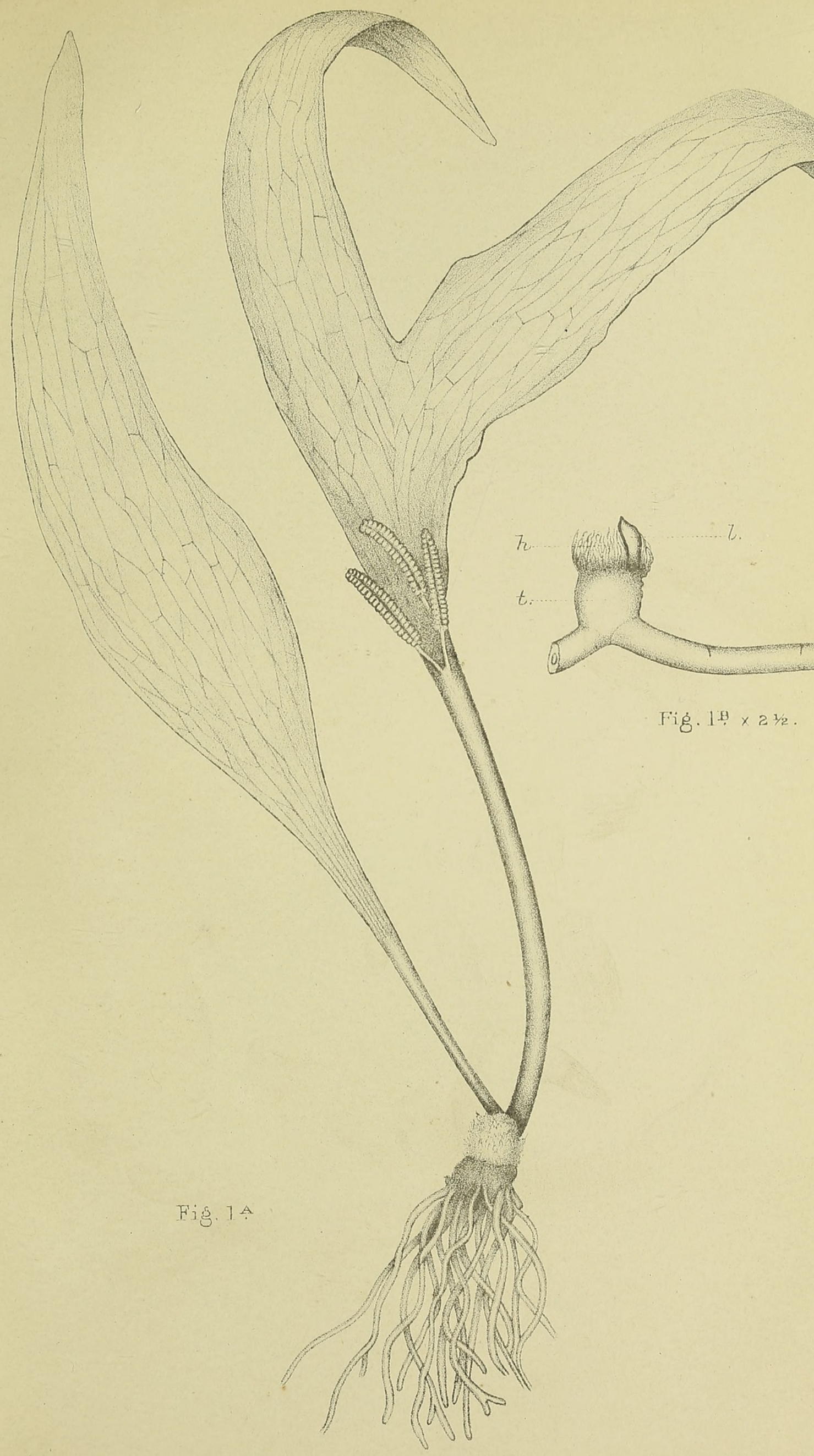


Annats of Botany,
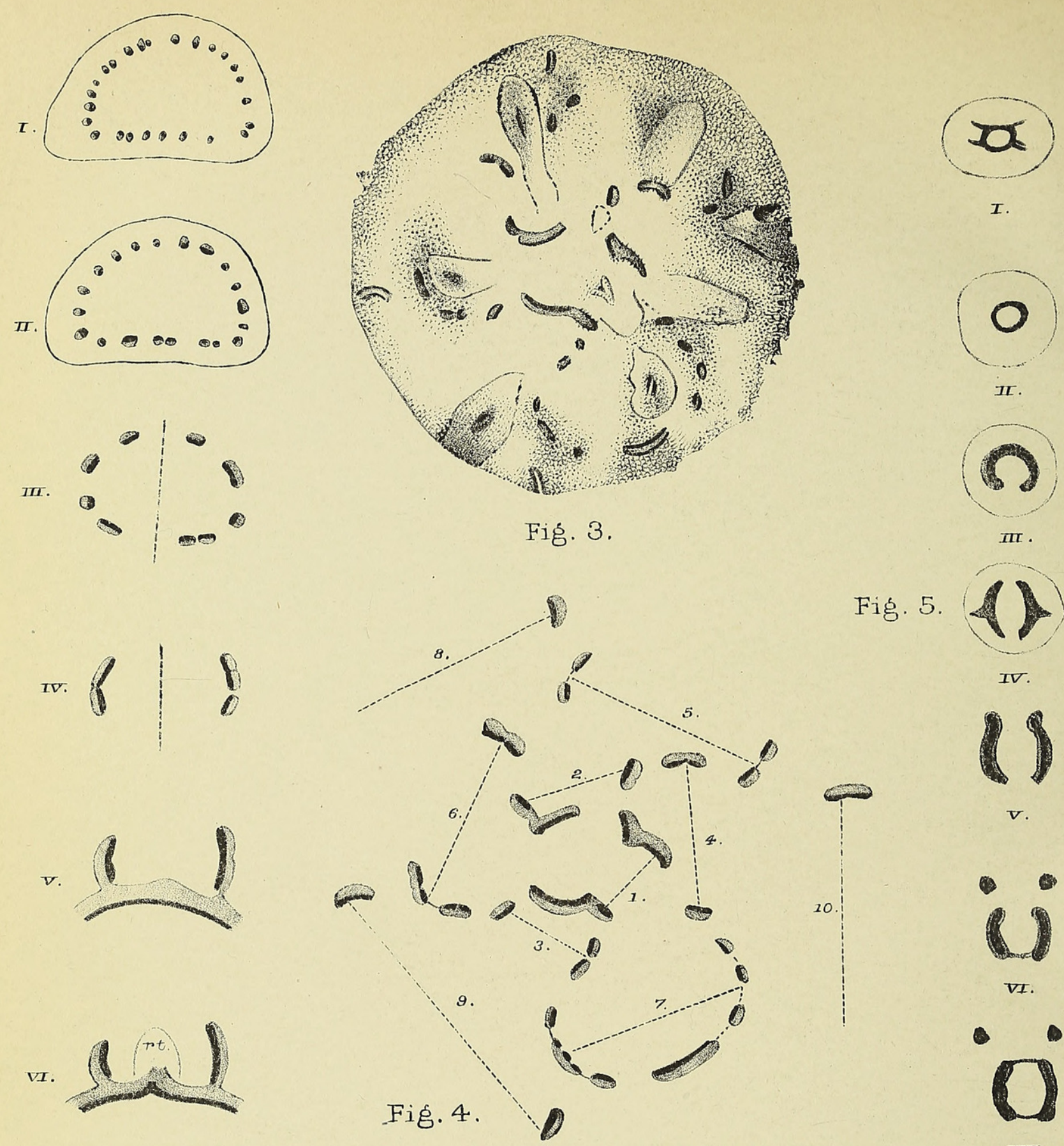
III.
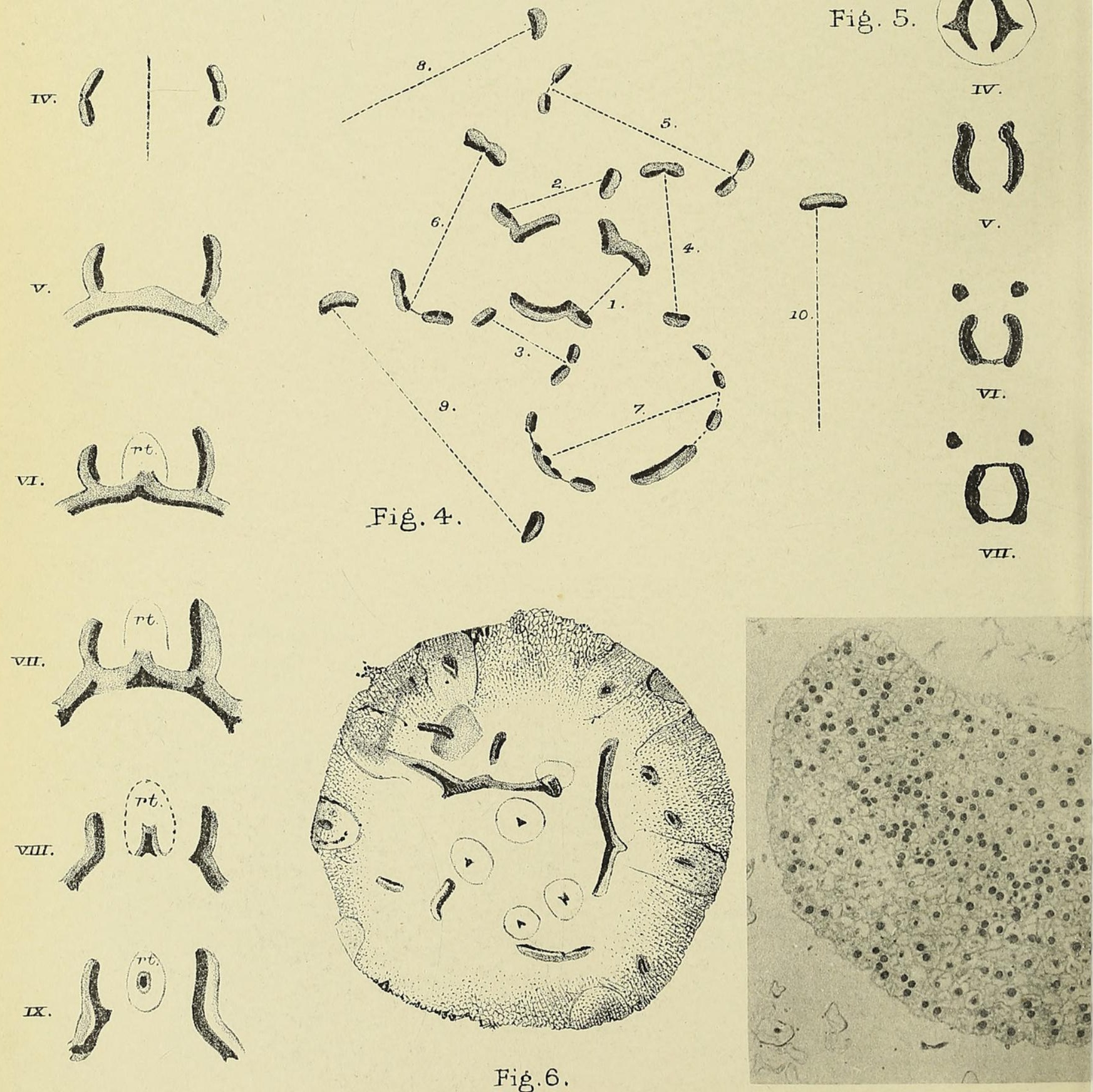

Fig. 2. $(1-1 x)$

Fig. 6. 


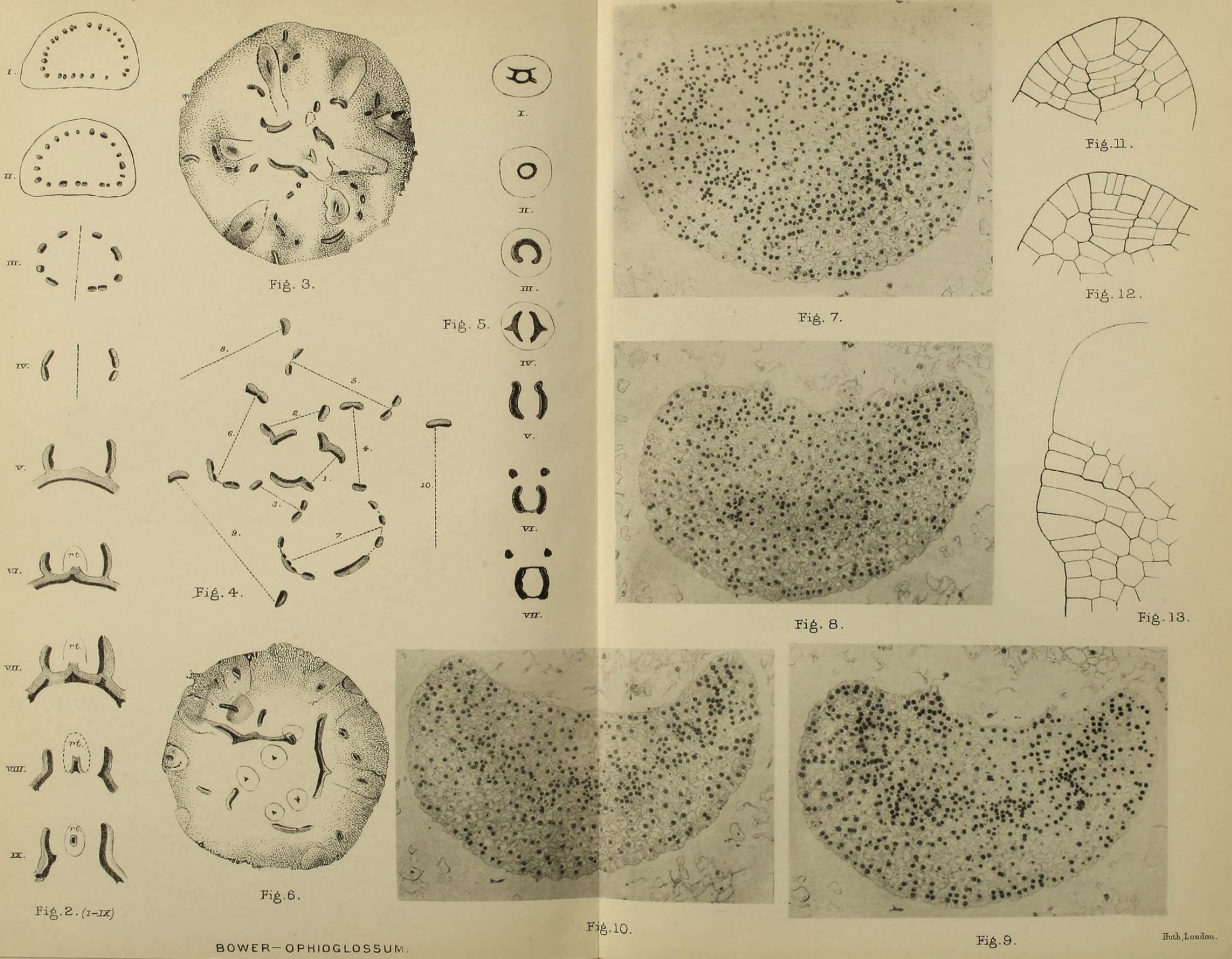


Annals of Botany,

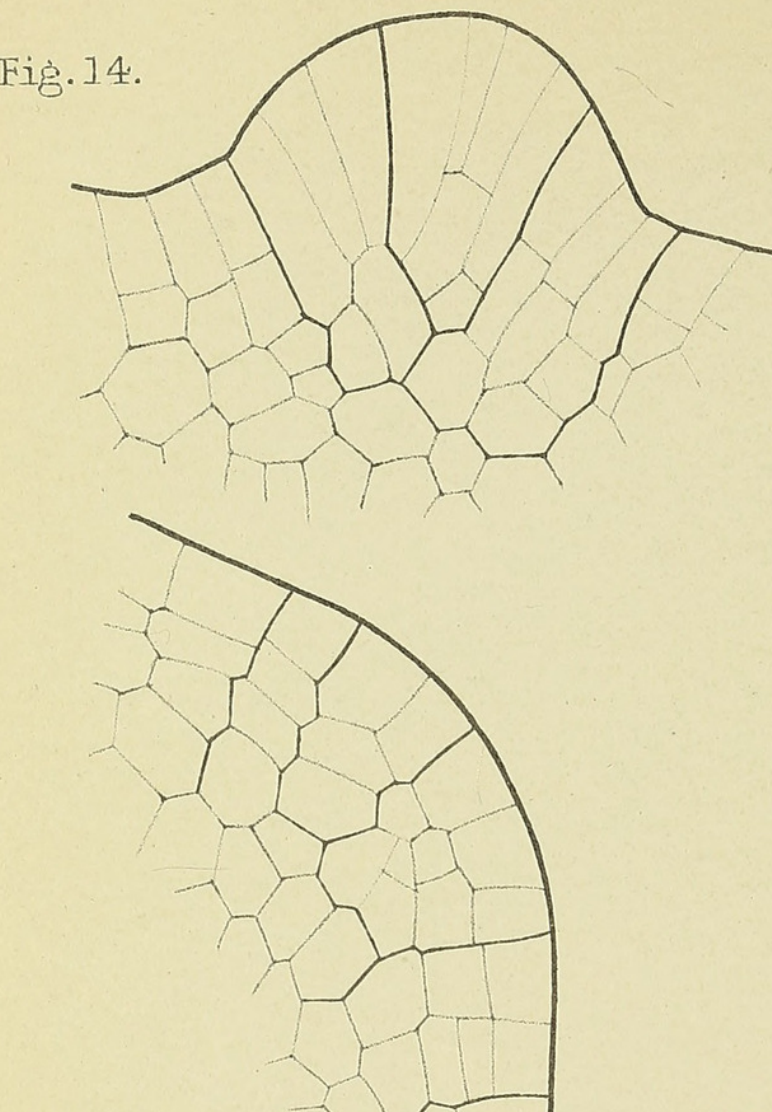

Fig. 17. (I-IX)
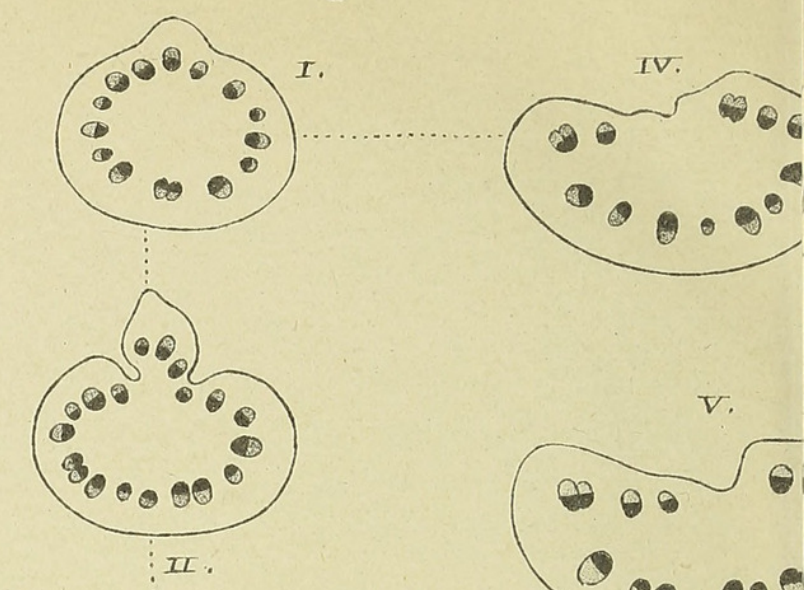

Fiǵ.15
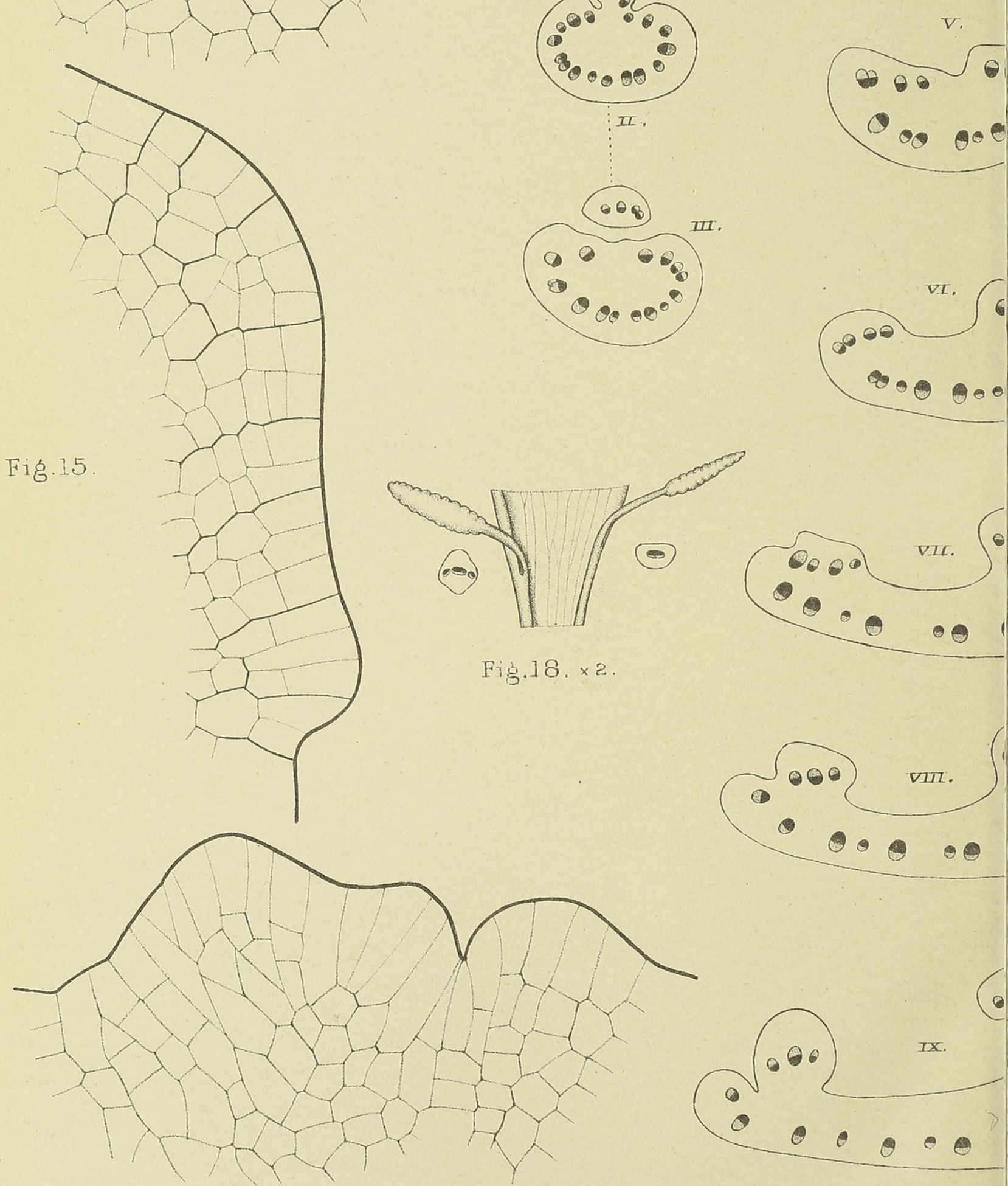

Fig.18. $\times 2$.
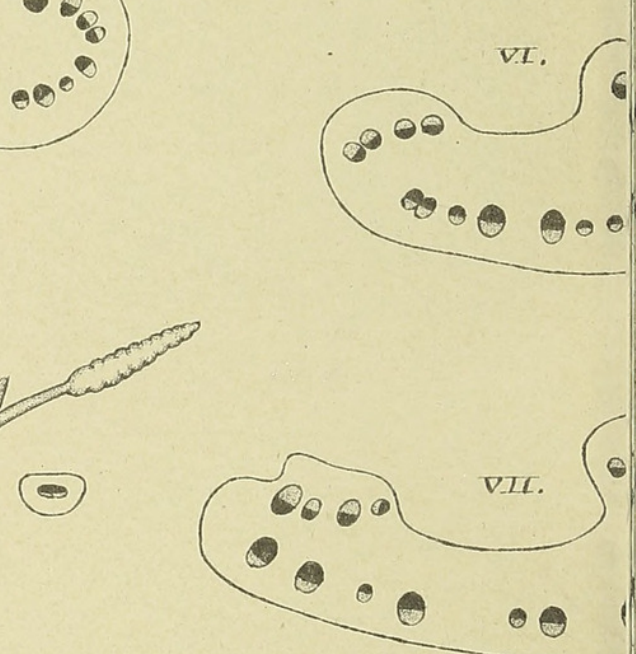
Fig. 19.(1-v)
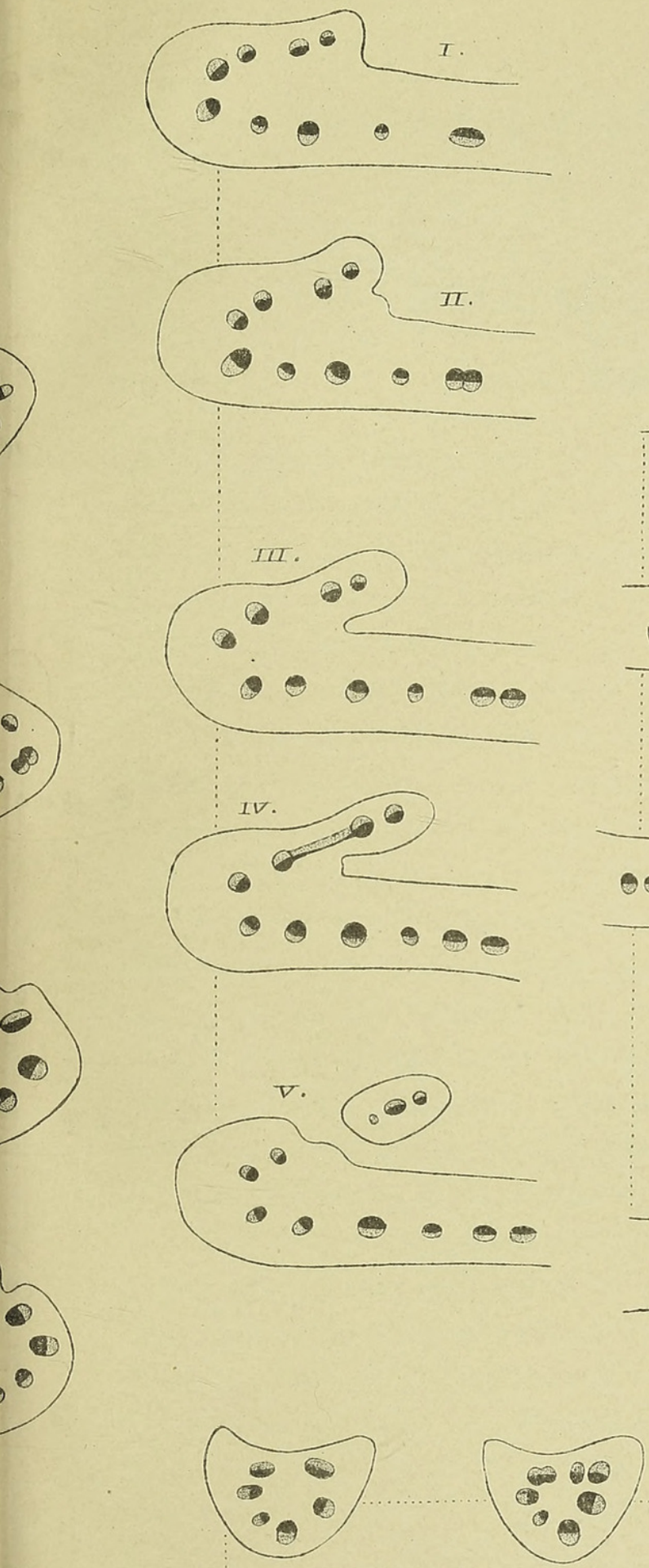

II.
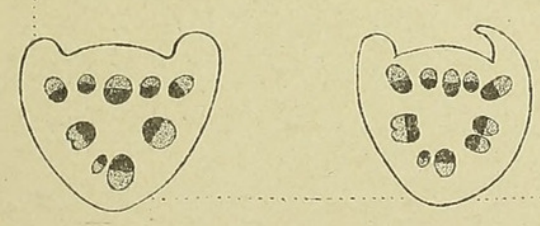

VII.
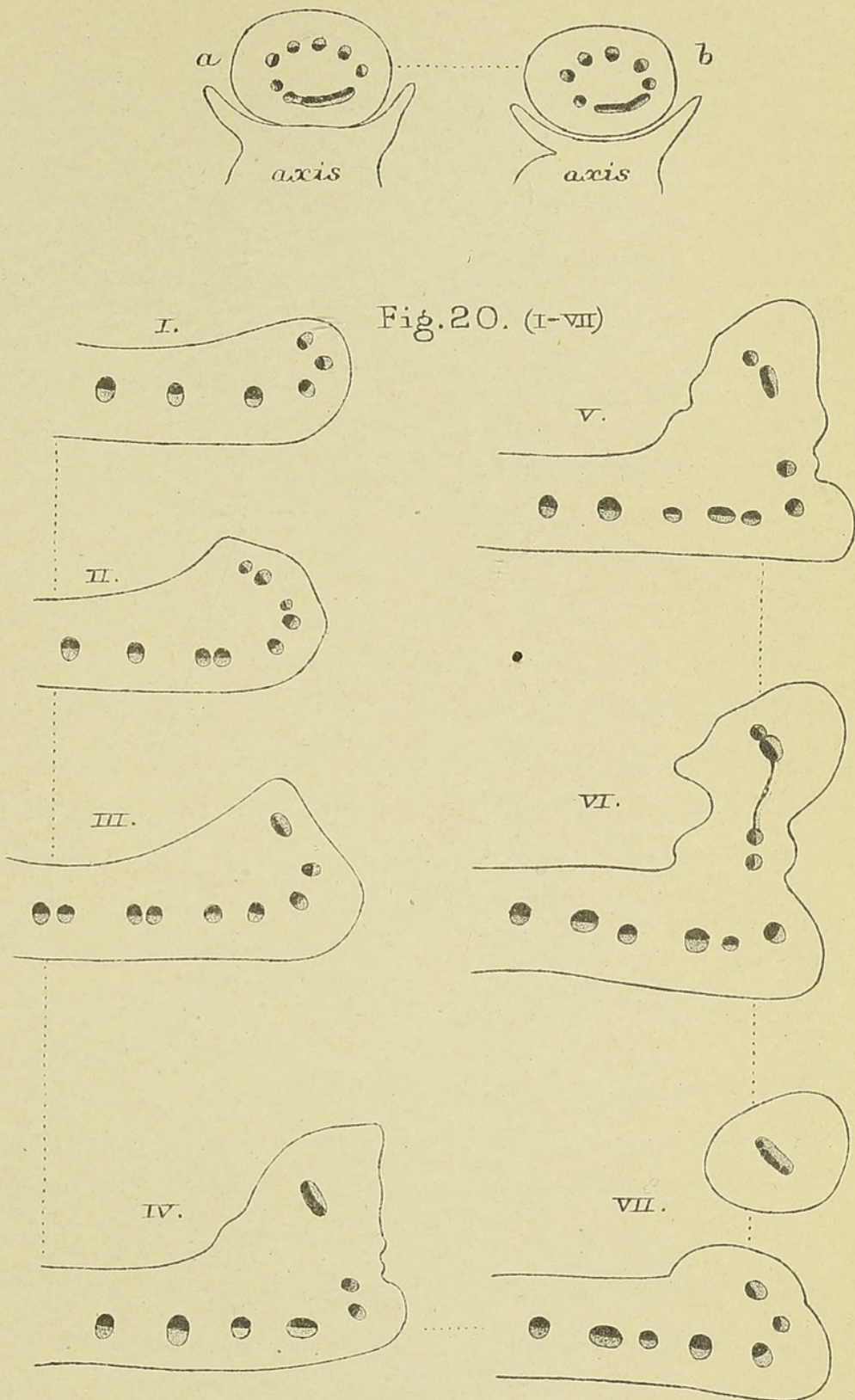

Fig. 2 2. (1-x

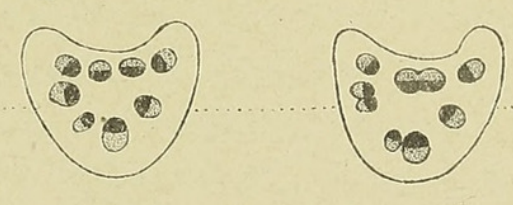

$\left(\frac{908}{0}\right)$

IV.

v.
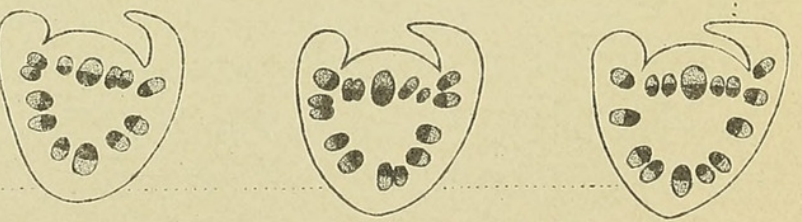

IX.

x. 


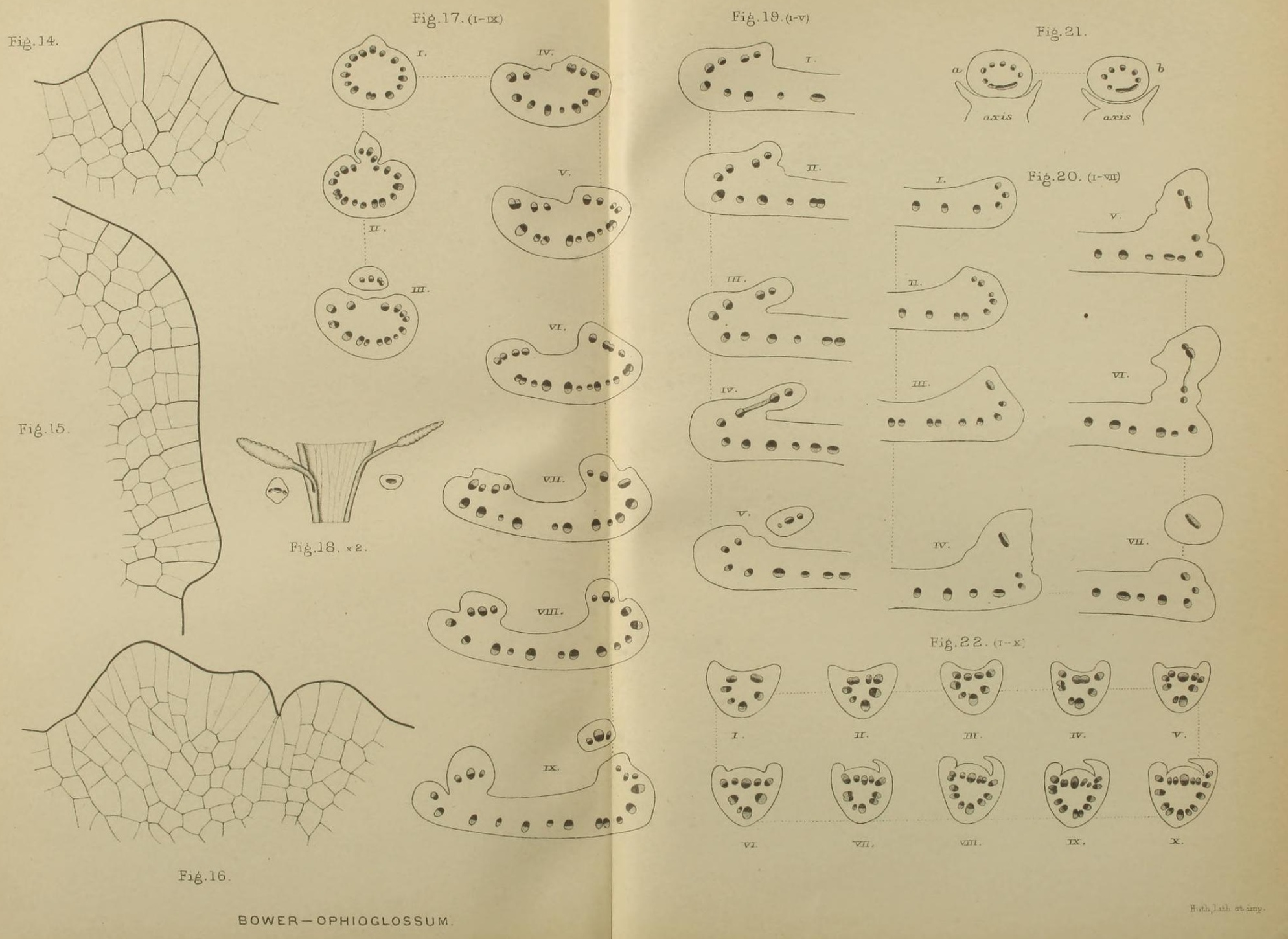




\section{$2 \mathrm{BHL}$ Biodiversity Heritage Library}

Bower, F. O. 1911. "Notes on the morphology of Ophioglossum (Cheiroglossa) palmatum, L." Annals of botany 25, 277-298.

https://doi.org/10.1093/oxfordjournals.aob.a089325.

View This Item Online: https://www.biodiversitylibrary.org/item/236971

DOI: https://doi.org/10.1093/oxfordjournals.aob.a089325

Permalink: https://www.biodiversitylibrary.org/partpdf/319833

\section{Holding Institution}

Smithsonian Libraries

\section{Sponsored by}

Biodiversity Heritage Library

\section{Copyright \& Reuse}

Copyright Status: Not in copyright. The BHL knows of no copyright restrictions on this item.

This document was created from content at the Biodiversity Heritage Library, the world's largest open access digital library for biodiversity literature and archives. Visit BHL at https://www.biodiversitylibrary.org. 